\title{
Evaluation of Endophytic Bacteria for their Influence on Plant Growth and Seed Germination under Water Stress Conditions
}

\author{
B.S. Manjunatha ${ }^{1 *}$, A.D. Asha ${ }^{1}$, N. Nivetha ${ }^{1}$, Bandeppa ${ }^{2}$, \\ V. Govindasamy ${ }^{1}$, M.S. Rathi ${ }^{1}$ and Sangeeta Paul ${ }^{1}$ \\ ${ }^{1}$ Division of Microbiology, ICAR-Indian Agricultural Research Institute, \\ New Delhi-110012, India \\ ${ }^{2}$ ICAR- Indian Institute of Rice Research, Hyderabad- 500030, India \\ *Corresponding author
}

\begin{abstract}
Keywords
Endophytic bacteria, Drought stress, Pearl millet, Osmotic stress, Seed germination, Seedling vigour.

Water stress,

Osmotolerance

Article Info

Accepted:

28 September 2017

Available Online:

10 November 2017 endophytic bacteria which are non-pathogenic. Endophytes are known to induce tolerance against drought and improve plant's resistance to drought. In this study, 31 endophytic bacterial isolates were evaluated for their alleviation of water stress in drought susceptible pearl millet (composite-443). In a pot experiment conducted under water stress condition, out of 31 isolates, inoculation with some of the isolates showed positive effect on shoot and root fresh weight and dry weight. The most promising 5 isolates were evaluated for their effect on seed germination and seedling vigour under osmotic stress conditions. It was observed that treatment with isolates MCL-1 and MKS-1 increased fresh weight of inoculated pearl millet seedling as compared to uninoculated control treatment exposed to osmotic stress. Increase in plumule length was observed for isolate MKS-1 and radicle length for both isolates MCL-1 and MKS-1 treated seeds under osmotic stress conditions. Effect of different levels of osmotic stress on the growth of these two isolates was studied using PEG 6000. It was observed that both isolates showed less than $25 \%$ reduction in growth in presence of 20\% PEG 6000 and there was more than 50\% growth reduction in presence of 30\% PEG 6000. At still higher concentration of PEG 6000, a drastic reduction in growth was observed. From the present investigation we can conclude that the isolates MCL-1 and MKS-1 show potential for development as bioinoculants for pearl millet for use under water stress conditions.
\end{abstract}

\section{A B S T R A C T}

Among environmental stresses drought is a major limiting factor that adversely affects crop growth and productivity worldwide and its incidence is predicted to increase under climate change. Drought adaptation of rainfed crops is major challenge to secure the agricultural productivity under current and future climate conditions. Plants harbour

\section{Introduction}

Drought is the most common abiotic stress factor affecting plant growth and development which is hindering agricultural productivity and causing economic losses in major parts of arid and semi-arid regions of the world. Global warming will further increase the severity and aggravation of drought in the future leading to a possible decrease in global food production. The situation will in future be even more severe as desertification will further increase and the current amount of annual loss of arable area may double by the end of the century because of global warming (IPCC, 2007). Inoculation of plants with 
beneficial micro-organisms promotes plant growth and enhances drought tolerance in arid or semiarid areas (Marulanda et al., 2007).

A variety of strategies used to improve the drought tolerance of crops, including traditional selection methods, molecular breeding programs and transgenic approaches are useful but are time consuming and resource intensive technologies (Flexas et al., 2013). However, recent reports have indicated the potential of microorganisms in improving plant's tolerance to abiotic stresses. Inoculation of Paenibacillus polymyxa confers drought tolerance in Arabidopsis thaliana was for the first time reported by (Timmusk et al., 1999). Whereas in case of wheat (Triticum aestivum) the inoculation of Azospirillum brasilense Sp245 under drought stress resulted in a better water status and an additional 'elastic adjustment' leading to better grain yield and mineral quality (Creus et al., 2004). Several PGPR are reported to induce drought stress tolerance in some plants such as maize, sunflower and green gram (Sandhya et al., 2009; Kasim et al., 2013).

PGPRs are adapted to adverse conditions and may protect plants from the deleterious effects of drought stress, thus increasing crop productivity in arid or semiarid areas (Kavamura et al., 2013). Therefore, identification and development eco-friendly strategies that can ameliorate plant growth in response to water stresses are an immediate need in agricultural systems that have to cope with the jeopardies of climate change. Endophytic bacteria may in future be even more important than rhizospheric bacteria, because it can escape competition from rhizospheric microorganisms and have more intimate contact with plant tissues. Endophytes are microbes which live inside plants without causing any disease to the plants and some of these may even confer benefits to their plant host such as abiotic stress reduction, increased vegetative and root growth (Hardoim et al., 2008). Keeping these facts in view, in the present investigation we screened the endophytic bacteria for their effect on growth of pearl millet crop under water stress conditions. The endophytic bacteria were then evaluated for their effect on seed germination, seedling vigour under osmotic stress conditions. Our outcome suggests that endophytic bacteria can be used in agriculture to reduce water stress in plants in an eco-friendly manner.

\section{Materials and Methods}

\section{Endophytic bacteria}

Thirty one osmotolerant endophytic bacteria isolated from pearl millet, mustard and cluster bean available in the germplasm of Division of Microbiology, IARI, New Delhi were used in the present study.

\section{Growth and maintenance of endophytic bacteria}

The endophytic bacteria were grown on nutrient agar medium. The stock cultures were maintained on slants of nutrient agar medium and were refrigerated at $4^{\circ} \mathrm{C}$. Subculturing was done as and when required.

\section{Screening for water deficit stress alleviation in pearl millet crop}

All the thirty one endophytic bacterial isolates were screened for their effect on plant growth under water stress under Phytotron conditions. Six inch plastic pots containing 1 $\mathrm{kg}$ soil were used for the experiment. Pearl millet seeds were inoculated with $48 \mathrm{hr}$ old broth cultures of endophytic bacterial cultures before sowing. Soil was maintained at 50\% field capacity (FC) from 15 days after sowing (DAS). In absolute control treatment uninoculated plants were maintained at field 
capacity and in control uninoculated treatment, plants were maintained at $50 \%$ FC. Three replications per treatment were maintained. Data on shoot, root fresh and dry weight was recorded 45 days after sowing (DAS).

Five cultures showing best performance for most of the parameters were selected for further studies.

\section{Plant germination and seedling vigour}

Seeds of pearl millet cultivar composite-443 were surface sterilized with $0.1 \% \quad \mathrm{HgCl}_{2}$ solution for 3 min followed by $70 \%$ ethanol for 30 seconds. These were then thoroughly washed with sterile water to remove traces of $\mathrm{HgCl}_{2}$ and ethanol.

The sterilized seeds were soaked in $48 \mathrm{hr}$ old broth cultures of the selected isolates for $1 \mathrm{hr}$ and then excess broth was drained. The seeds were then kept for germination on petriplates containing $0.8 \%$ sterile agar supplemented with $0 \%$ and 20\% PEG 6000. Appropriate uninoculated controls were maintained. Ten seeds per petriplate and three replications of each treatment were maintained. Plates were incubated at $28 \pm 2^{0} \mathrm{C}$ for 3 days. After 3 days, data on percent seed germination, fresh weight of seedling and radicle and plumule length were recorded.

Two most promising isolates were selected on the basis of seed germination, fresh weight of seedlings, radicle and plumule length for further studies.

\section{Effect of osmotic stress on growth of the selected isolates}

Nutrient broth supplemented with different concentrations of PEG 6000 (0\%, 20\%, 30\%, $40 \%$ and $50 \%$ ) were used to study the effect of osmotic stress on the selected isolates.
Appropriate uninoculated controls were used. The tubes were inoculated with $2 \%$ inoculum of the selected isolates and incubated at $28 \pm 2^{\circ} \mathrm{C}$ for $48 \mathrm{hr}$ on an orbital shaker. Growth of the isolates on different concentrations of PEG 6000 was determined by taking O.D. at $600 \mathrm{~nm}$ using a spectrophotometer.

\section{Statistical analysis}

All the statistical analysis was done using OPSTAT statistical software.

\section{Results and Discussion}

Screening for water stress alleviation in pearl millet crop by the selected endophytic bacterial isolates

Out of the 31 isolates screened, inoculation with only 6 endophytic bacteria was observed to significantly improve shoot fresh weight under water stress conditions (Table 1). Highest shoot fresh weight was observed due to inoculation with isolate MKS-1.

Other isolates which improved shoot fresh weight were KPSR-2, MCL-1, MMS-3, MMS-5 and MAS-2. Only three isolates namely MMS-3, MAL-2 and MAL-3 improved root fresh weight. Only three isolates significantly improved root dry weight namely CPSR-2, MMS-3 and MAL-2 while shoot dry weight was significantly enhanced by isolates MMS-3 and MKS-1.

Plant growth promoting endophytic bacterial inoculation minimized the drought stress imposed effects significantly by increasing shoot biomass and root biomass in maize (Naveed et al., 2014). Burkholderia phytofirmans Ps JN was observed to colonize the endosphere and promote growth and enhance abiotic and biotic stress tolerance in a variety of horticultural crops, e.g. potatoes, tomato and grapevine (Mitter et al., 2013). 
Table.1 Effect of the selected osmotolerant endophytic bacteria on plant growth under water stress conditions

\begin{tabular}{ccccc}
\hline Treatments* & Shoot & $\begin{array}{l}\text { Root } \\
\text { FW (g) }\end{array}$ & $\begin{array}{l}\text { Shoot }(\mathbf{g}) \\
\text { DW(g) }\end{array}$ & $\begin{array}{l}\text { Root } \\
\text { DW(g) }\end{array}$ \\
\hline 100\% FC** & 33.73 & 2.93 & 6.83 & 0.73 \\
50\% FC & 23.42 & 1.17 & 3.85 & 0.4 \\
NAD-3 & 12.47 & 0.40 & 2.12 & 0.22 \\
NAD-7 & 15.40 & 0.75 & 2.48 & 0.36 \\
NAD-9 & 12.53 & 0.53 & 2.13 & 0.24 \\
NAD-17 & 20.77 & 0.93 & 3.32 & 0.38 \\
MRD-4 & 20.93 & 0.85 & 2.79 & 0.44 \\
MRD-8 & 19.00 & 0.68 & 3.34 & 0.31 \\
MRD-9 & 20.67 & 0.88 & 3.51 & 0.44 \\
MRD-17 & 20.23 & 1.16 & 2.85 & 0.45 \\
RPRL-14 & 22.57 & 1.05 & 3.56 & 0.39 \\
KPSR-2 & 26.33 & 1.39 & 4.22 & 0.47 \\
KPSR-17 & 23.50 & 1.13 & 3.13 & 0.38 \\
KPRL-6 & 24.43 & 1.11 & 3.16 & 0.33 \\
KPRL-10 & 15.86 & 0.70 & 2.82 & 0.32 \\
KPRR-22 & 11.27 & 0.84 & 2.06 & 0.32 \\
KPSS-13 & 22.10 & 0.86 & 2.12 & 0.39 \\
KPSR-5 & 23.33 & 1.00 & 3.89 & 0.41 \\
CPSR-2 & 18.79 & 1.06 & 2.92 & 0.50 \\
RPSL-9 & 17.56 & 0.60 & 2.87 & 0.27 \\
RPSL-2 & 15.43 & 0.96 & 2.57 & 0.31 \\
RPSR-5 & 24.00 & 0.82 & 3.78 & 0.40 \\
MCL-1 & 27.37 & 1.30 & 4.16 & 0.58 \\
MMS-3 & 29.30 & 1.43 & 4.99 & 0.49 \\
MMS-5 & 30.67 & 1.36 & 3.98 & 0.43 \\
MMR-1 & 20.96 & 0.97 & 4.52 & 0.43 \\
MKS-1 & 32.33 & 1.20 & 5.03 & 0.36 \\
MKL-4 & 15.30 & 1.06 & 2.62 & 0.41 \\
MKR-2 & 20.53 & 1.08 & 2.80 & 0.30 \\
MAS-1 & 17.27 & 1.38 & 2.68 & 0.40 \\
MAS-2 & 26.67 & 1.28 & 3.74 & 0.47 \\
MAL-2 & 23.20 & 1.40 & 3.56 & 0.59 \\
MAL-3 & 25.87 & 1.52 & 4.11 & 0.47 \\
SEm \pm & 1.041 & 0.08 & 0.30 & 0.03 \\
CD at 5\% & 2.94 & 0.23 & 0.86 & 0.09 \\
\hline
\end{tabular}

* Except for absolute control treatment in all the other treatments soil was maintained at $50 \%$ field capacity ** Uninoculated control treatment with soil maintained at field capacity

Values are means of three replications 
Table.2 Effect of the selected osmotolerant isolates on percent germination and seedling vigour of pearl millet under osmotic stress

\begin{tabular}{|c|c|c|c|c|c|c|c|c|}
\hline \multirow[t]{2}{*}{ Isolates } & \multicolumn{2}{|c|}{ Seed germination $(\%)$} & \multicolumn{2}{|c|}{ Plumule length $(\mathrm{cm})$} & \multicolumn{2}{|c|}{ Radicle length (cm) } & \multicolumn{2}{|c|}{ Fresh weight (mg) } \\
\hline & Control & $20 \% *$ & Control & $20 \%$ & Control & $20 \%$ & Control & $20 \%$ \\
\hline Uninoculated & 83.33 & 83.33 & 1.29 & 0.607 & 1.84 & 1.33 & 288.33 & 175.67 \\
\hline KPSR2 & 80.00 & 51.67 & 1.48 & 0.400 & 0.47 & 1.25 & 256.00 & 192.33 \\
\hline MCL-1 & 86.67 & 83.33 & 1.65 & 0.617 & 2.89 & 1.45 & 300.67 & 205.33 \\
\hline MMS-3 & 56.67 & 70.00 & 1.23 & 0.383 & 2.44 & 1.11 & 268.33 & 177.33 \\
\hline MMS-5 & 61.67 & 63.33 & 1.40 & 0.337 & 1.51 & 1.33 & 267.67 & 168.00 \\
\hline MKS-1 & 90.00 & 83.33 & 1.56 & 0.697 & 2.95 & 1.57 & 350.33 & 213.67 \\
\hline $\mathrm{SEm} \pm$ & 5.813 & 3.66 & 0.032 & 0.024 & 0.14 & 0.018 & 9.219 & 3.702 \\
\hline $\mathrm{CD}$ at $\overline{5} \%$ & 18.111 & 11.42 & 0.099 & 0.075 & 0.436 & 0.055 & 28.72 & 11.533 \\
\hline
\end{tabular}

Values are means of three replications

* $20 \%$ PEG 6000 concentration

Table.3 Effect of osmotic stress on growth of the selected osmotolerant endophytic bacteria

\begin{tabular}{ccc} 
Treatments & \multicolumn{2}{c}{ Growth obtained (in O.D.) } \\
\cline { 2 - 3 } Control & MCL-1 & MKS-1 \\
\cline { 2 - 3 } 20\% PEG & 0.69 & 0.70 \\
30\% PEG & 0.55 & 0.58 \\
40\% PEG & 0.31 & 0.21 \\
50\% PEG & 0.13 & 0.12 \\
SEm \pm & 0.04 & 0.07 \\
CD at $5 \%$ & 0.01 & 0.007 \\
\hline
\end{tabular}

Values are means of three replications

Fig.1 Effect of inoculation with osmotolerant endophytic bacteria on pearl millet seed germination

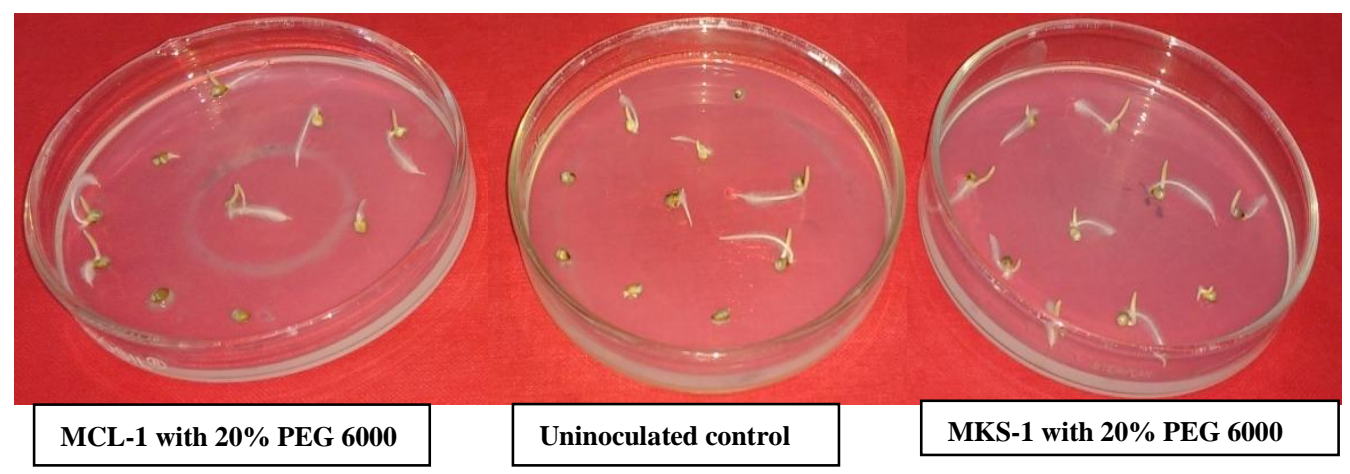

Increase in the total root system is the most commonly reported plant response mediated by PGPB inoculation in various plant species (Lucy et al., 2004). Our observations are in accord with previous reports on the potential of endophytic bacteria in improving plant productivity and enhancing drought tolerance in plants (Vardharajula et al., 2011). 
Effect of endophytic bacterial isolates on seed germination and seedling vigour under osmotic stress

No effect of osmotic stress on seed germination was observed. Under both no stress and osmotic stress conditions $83.33 \%$ seed germination was observed in uninoculated control treatments (Table 2). Although, inoculation with isolate MKS-1 did improve seed germination under no stress condition, it was statistically at par with control treatment. Under osmotic stress condition no positive effect of inoculation on seed germination was observed. However, under both these conditions inoculation with some of the cultures had a negative effect on seed germination viz. MMS-3 and MMS-5 under no stress condition and KPSR-2 and MMS-5 under osmotic stress condition.

Seedling vigour was improved due to inoculation with most of isolates under no stress conditions as indicated by increased radicle and plumule length of seedling (Fig.1 and Table 3). Under osmotic stress conditions, inoculation with isolate MKS-1 significantly improved plumule length while both the isolates MKS-1 and MCL-1 significantly improved radicle length and seedling fresh weight.. In general, inoculation with PGPRs can enhance germination and seedling emergence (Zahir 2004). Pearl millet was protected from inhibitory effects of drought stress by the bacterial endophytes (Naveed et al., 2014). Osmotolerant rhizobacteria improved seed germination and seedling vigour in mustard under osmotic stress conditions (Bandeppa et al., 2015).

\section{Screening of endophytic bacterial isolates for osmotolerance}

Both the isolates MKS-1 and MCL-1 which improved shoot and root growth as well as improved seedling fresh weight were selected and effect of osmotic stress on their growth was studied. It was observed that in presence of 20\% PEG 6000 there was less than $25 \%$ reduction in growth of these isolates (Table 3) indicating these isolates to be moderately tolerant to osmotic stress. However, in presence of 30\% PEG 6000 there was more than $50 \%$ reduction in their growth. Although, the isolates were able to grow in presence of $40 \%$ and 50\% PEG 6000, growth was drastically reduced. Recent reports have also indicated the ability of osmotolerant bacteria to grow in medium in presence of $40 \%$ PEG 6000 (Bandeppa et al., 2015). However, osmotic stress is known to affect growth of bacteria (Malakar et al., 2014), which supported our observations.

\section{References}

Bandeppa, Paul, S., Kandpal, B.K. 2015. Evaluation of osmotolerant rhizobacteria for alleviation of water deficit stress in mustard. Green Farming., (3): 590-593.

Creus, C.M., Sueldo, R.J., Barassi, C.A. 2004. Water relations and yield in Azospirillum-inoculated wheat exposed to drought in the field. Can.J. Bot., 82:273-281.

Flexas, J., Niinemets, U., Galle, A., Barbour, M.M. 2013. Diffusional conductances to $\mathrm{CO}$ as a target for increasing photosynthesis and photosynthetic water-use efficiency. Photosynth. Res., 117: $1-3$

Hardoim, P.R., Overbeek, V., Leo, S., Elsas, D.J.V. 2008. Properties of bacterial endo-phytes and their proposed role in plant growth. Trends in Microbio., 16:463-471.

Jamil, M., Lee, D. B., Jung, K. Y., Ashraf, M., Lee, S.C., Rhal,E.S. 2006. Effect of salt $(\mathrm{NaCl})$ stress on germination and early seedling growth of four vegetables species. Cent. Eur. Agric.,7:273-282.

Kasim, W.A., Osman, M.E., Omar, M.N., Abd El-Daim, I.A., Bejai, S., Meijer, J. 
2013. Control of drought stress in wheat using plant growth-promoting bacteria. J. Plant Growth Regula., 32: 122-130.

Kavamura, V.N., Santos, S.N., da Silva, J.L., Parma, M.M., Ávila, L.A., Visconti, A., Zucchi,T.D., Taketani, R.G., Andreote, F.D., de Melo, I.S. 2013. Screening of Brazilian cacti rhizobacteria for plant growth promotion under drought. Microbiologi.Rese., 168: 183-191.

Lucy, M., Reed, E., Glick, B.R. 2004. Applications of free living plant growth-promoting rhizobacteria. Antonie van Leeuwenhoek., 86: 1-25.

Malakar P., Singh, V.K., Karmarkar, R and Venkatesh, K.V. 2014. Effect of $\beta$ galactosidase synthesis and burden on growth of osmotic stress in Escherichia coli. Springer Plus., 3:748

Marulanda, A., Porcel, R., Barea, J., Azcón, R. 2007. Drought tolerance and antioxidant activities in lavender plants colonized by native drought-tolerant or drought-sensitive Glomus species. Microbial. Ecol., 54:543-552.

Mitter, B., Petric, A., Shin, M.W., Chain, P.S.G., Hauberg-Lotte, L., ReinholdHurek,B., Nowak, J., Sessitsch, A. 2013. Comparative genome analysis of Burkholde-ria phytofirmans PsJN reveals a wide spectrum of endophytic lifestyles basedon interaction strategies with host plants. Front. Plant Sci., 10:3389.

Naveed, M., Birgit M., Thomas G., Reichenauerb., Krzysztof W., Angela S. 2014. Increased drought stress resilience of maize through endophyticcolonization by Burkholderia phytofirmans PsJN and Enterobactersp. FD17. Environ. Experi. Bota., 97 : 3039.

Sandhya, V., Ali, S.Z., Grover, M., Reddy, G., Venkateswarlu, B. 2009. Alleviation of drought stress effects in sunflower seedlings by the exopolysaccharides pro-ducing Pseudomonas putida strain GAP-P45. Biol. Ferti. soils., 46:17-26.

Solomon, S., Qin, D., Manning, M., Chen, Z.S., Marquis, F.M., Averyt, K.B., Tignor, M., Miller, H.L.(Eds.), IPCC. 2007. Climate change, the physical science basis. Contribution of Working Group I to the Fourth Assessment Report of the Intergovernmental Panel on Climate Change. Cambridge University Press, Cambridge, 996 p.

Timmusk, S., Wagner, E.G. 1999. The plantgrowth-promoting rhizobacterium Paenibacillus polymyxa induces changes in Arabidopsis thaliana gene expression: a possible connection between biotic and abiotic stress responses. Molecu. Plant Micro. Interact, 12: 951-959.

Vardharajula, S., Ali, S.Z., Grover, M., Reddy, G., Bandi, V. 2011. Droughttolerantplant growth promoting Bacillus spp.: effect on growth, osmolytes, and antiox-idant status of maize under drought stress. J. Plant Inte., 6: 1-14.

Zahir, Z. A., Arshad, M., Frankenberger, W.T. 2004. Plant growth promoting rhizobacteria: applications and perspectives in agriculture. Advan. Agro., 81: 97-168.

\section{How to cite this article:}

Manjunatha, B.S., A.D. Asha, N. Nivetha, Bandeppa, V. Govindasamy, M.S. Rathi and Sangeeta Paul. 2017. Evaluation of Endophytic Bacteria for their Influence on Plant Growth and Seed Germination under Water Stress Conditions. Int.J.Curr.Microbiol.App.Sci. 6(11): 4061-4067. doi: https://doi.org/10.20546/ijcmas.2017.611.475 